\title{
Association of abnormal carbon dioxide levels with poor neurological outcomes in aneurysmal subarachnoid hemorrhage: a retrospective observational study
}

Shota Yokoyama ${ }^{1 *+} \mathbb{D}$, Toru Hifumi ${ }^{2 \dagger}$, Tomoya Okazaki $^{3}$, Takahisa Noma ${ }^{1}$, Kenya Kawakita ${ }^{3}$, Takashi Tamiya ${ }^{4}$, Tetsuo Minamino ${ }^{1}$ and Yasuhiro Kuroda ${ }^{3}$

\begin{abstract}
Background: In patients with aneurysmal subarachnoid hemorrhage (SAH), an association between hypocapnia and poor clinical outcomes has been reported. However, the optimal arterial carbon dioxide tension $\left(\mathrm{PaCO}_{2}\right)$ remains unknown. The present retrospective study aimed to examine the association of abnormal $\mathrm{PaCO}_{2}$ levels with neurological outcomes and investigate the optimal target $\mathrm{PaCO}_{2}$ level in patients with $\mathrm{SAH}$.

Methods: We retrospectively selected consecutive adult patients hospitalized in the intensive care unit (ICU) for SAH between January 2009 and April 2017. Univariate and multivariate analyses were performed to identify the independent predictors of unfavorable neurological outcomes (i.e., modified Rankin scale score of 3-6 on hospital discharge).

Results: Among 158 patients with SAH, 73 had unfavorable neurological outcomes. During the first 2 weeks in the ICU, the median number of $\mathrm{PaCO}_{2}$ measurements per patient was 43 . The factors significantly associated with unfavorable neurological outcomes were age, Hunt and Kosnik grade, maximum lactate levels during the first $24 \mathrm{~h}$, and maximum (odds ratio [OR], 1.12; 95\% confidence interval [Cl], 1.03-1.21; $p<0.01)$ and minimum $\mathrm{PaCO}_{2}$ levels $(\mathrm{OR}, 0.81 ; 95 \% \mathrm{Cl}$, $0.72-0.92 ; p<0.01)$. Receiver operating characteristic curve analysis revealed that the cutoff range of $\mathrm{PaCO}_{2}$ was $30.2-$ $48.3 \mathrm{mmHg}$. Unfavorable neurological outcomes were noted in $78.8 \%$ of patients with $\mathrm{PaCO}_{2}$ levels outside this range and in $22.8 \%$ of patients with $\mathrm{PaCO}_{2}$ levels within this range.

Conclusions: Both the maximum and minimum $\mathrm{PaCO}_{2}$ levels during ICU management in patients with $\mathrm{SAH}$ were significantly associated with unfavorable neurological outcomes. Further prospective studies are required to validate our findings and explore their clinical implications. Our findings may provide a scientific rationale for these future prospective studies.
\end{abstract}

Keywords: Subarachnoid hemorrhage, $\mathrm{PaCO}_{2}$, Hypocapnia, Hypercapnia, Intensive care unit, Neurological outcome, Delayed cerebral ischemia

\footnotetext{
* Correspondence: sho05m088@med.kagawa-u.ac.jp

† Shota Yokoyama and Toru Hifumi contributed equally to this work. 1 Department of Cardiorenal and Cerebrovascular Medicine, Kagawa University Hospital, 1750-1 Ikenobe, Miki, Kita, Kagawa 761-0793, Japan Full list of author information is available at the end of the article
}

(C) The Author(s). 2018 Open Access This article is distributed under the terms of the Creative Commons Attribution 4.0 International License (http://creativecommons.org/licenses/by/4.0/), which permits unrestricted use, distribution, and reproduction in any medium, provided you give appropriate credit to the original author(s) and the source, provide a link to the Creative Commons license, and indicate if changes were made. The Creative Commons Public Domain Dedication waiver (http://creativecommons.org/publicdomain/zero/1.0/) applies to the data made available in this article, unless otherwise stated. 


\section{Background}

Aneurysmal subarachnoid hemorrhage (SAH) accounts for a reasonably large proportion of stroke-related mortality cases. The overall mortality in patients with $\mathrm{SAH}$ is over $30 \%$, and approximately $10-20 \%$ of survivors show functional dependence despite intensive neurological care $[1,2]$. Several extensive studies have been conducted to improve intensive neurological care in patients with $\mathrm{SAH}$ [3-8].

Cerebral blood flow $(\mathrm{CBF})$ is mainly regulated by arterial carbon dioxide tension $\left(\mathrm{PaCO}_{2}\right)[9,10]$. Abnormal $\mathrm{PaCO}_{2}$ levels are considered to cause major changes in $\mathrm{CBF}$ through vasoconstriction and vasodilation, respectively, possibly contributing to further brain injury [11, 12]. Additionally, a previous systematic review demonstrated abnormal $\mathrm{PaCO}_{2}$ levels to be associated with poor clinical outcomes in patients with traumatic brain injury (TBI), post-cardiac arrest patients, and stroke patients [13]; therefore, $\mathrm{PaCO}_{2}$ control in the intensive care unit (ICU) can greatly influence the management of patients with SAH. Several studies have reported that hypocapnia (defined as $\mathrm{PaCO}_{2}<35 \mathrm{mmHg}$ ), albeit unintentional, may be a common and under-recognized cause of brain tissue hypoxia after SAH and may be associated with poor neurological outcomes and a high incidence of delayed cerebral ischemia (DCI) [14-16]. However, the association between hypercapnia (defined as $\mathrm{PaCO}_{2}$ $>45 \mathrm{mmHg}$ ) and neurological outcomes in patients with SAH has not been examined.

The present guidelines for the management of $\mathrm{SAH}$ do not specify the target $\mathrm{PaCO}_{2}$ level $[17,18]$. Recently, a phase I study involving poor-grade $\mathrm{SAH}$ patients demonstrated that CBF increased after controlled hypercapnia by up to $60 \mathrm{mmHg}$, even during periods of vasospasm [10]. Another study involving resuscitated cardiac arrest patients reported that the levels of neuron-specific enolase were lower with targeted therapeutic mild hypercapnia $\left(\mathrm{PaCO}_{2}, 50-55 \mathrm{mmHg}\right)$ than with normocapnia $\left(\mathrm{PaCO}_{2}, 35-45 \mathrm{mmHg}\right)$ [19]. Therefore, it is unknown whether hypercapnia is permitted and whether there is an optimal target $\mathrm{PaCO}_{2}$ level in patients with $\mathrm{SAH}$.

The present study aimed to examine the association of abnormal $\mathrm{PaCO}_{2}$ levels with unfavorable neurological outcomes and investigate the target $\mathrm{PaCO}_{2}$ level in patients with $\mathrm{SAH}$ for further prospective studies.

\section{Materials and methods}

\section{Study design and setting}

This single-center, retrospective, observational study was performed at Kagawa University Hospital, a 613-bed teaching institution with an 8-bed ICU managed by a neurointensivist. The patient medical records were reviewed after receiving approval from the institutional review board (approval number H29-090), and the study was performed in accordance with the ethical standards established in the
1964 Declaration of Helsinki and its later amendments. The institutional review board approved a waiver of the requirement for individual consent. If patients did not want to participate in the current study, they could request to be excluded.

\section{Study participants and inclusion criteria}

The study included patients aged $>18$ years who were consecutively admitted to the ICU with a confirmed diagnosis of SAH between January 1, 2009, and April 15, 2017, and who had at least five available arterial blood gas (ABG) analyses. The exclusion criteria were a history of pregnancy or trauma, presence of acute lung injury/ acute respiratory distress syndrome or severe heart failure requiring positive-pressure ventilation during the first 2 weeks in the ICU, and provision of only comfort care (Fig. 1).

\section{General management of SAH in the ICU}

All the patients with SAH were managed in accordance with the Guidelines for the Management of Aneurysmal Subarachnoid Hemorrhage by the American Heart Association/American Stroke Association [8, 18]. In addition to general intensive care, all the patients were monitored for clinical deterioration or for the development of cerebral infarction owing to DCI. Using previously published criteria, DCI was defined as either (1) the development of new focal neurological signs or deterioration of the consciousness level thought to be caused by the presence of ischemia after the exclusion of other possible causes or (2) the appearance of new infarcts caused by vasospasm on CT or MRI [15, 20]. Fluid management was targeted to maintain euvolemia. Induced hypertension and hemodilution were not performed, and mannitol or hypertonic saline solution was not administered. The patients received minimum amounts of sedatives, such as propofol, midazolam, and dexmedetomidine, which were necessary to prevent ventilator dyssynchrony and patient discomfort. Analgesics, including acetaminophen, nonsteroidal anti-inflammatory medications, and fentanyl, were administered as required. Fever was treated aggressively with acetaminophen, nonsteroidal anti-inflammatory medications, or cooling devices. Active maintenance of normothermia was not routinely performed.

\section{Control of $\mathrm{PaCO}_{2}$ levels in patients with $\mathrm{SAH}$ in the ICU}

ABG analyses, including $\mathrm{PaCO}_{2}$, were routinely performed every $6 \mathrm{~h}$ during the first 2 weeks in the ICU, and additional measurements were obtained by critical care physicians as needed. Patients were typically managed in the ICU during the first 2 weeks with reference to $A B G$ analyses data, considering the timing of DCI occurrence. For patients in whom the arterial line could be withdrawn and who could be discharged from the ICU at an early stage, 


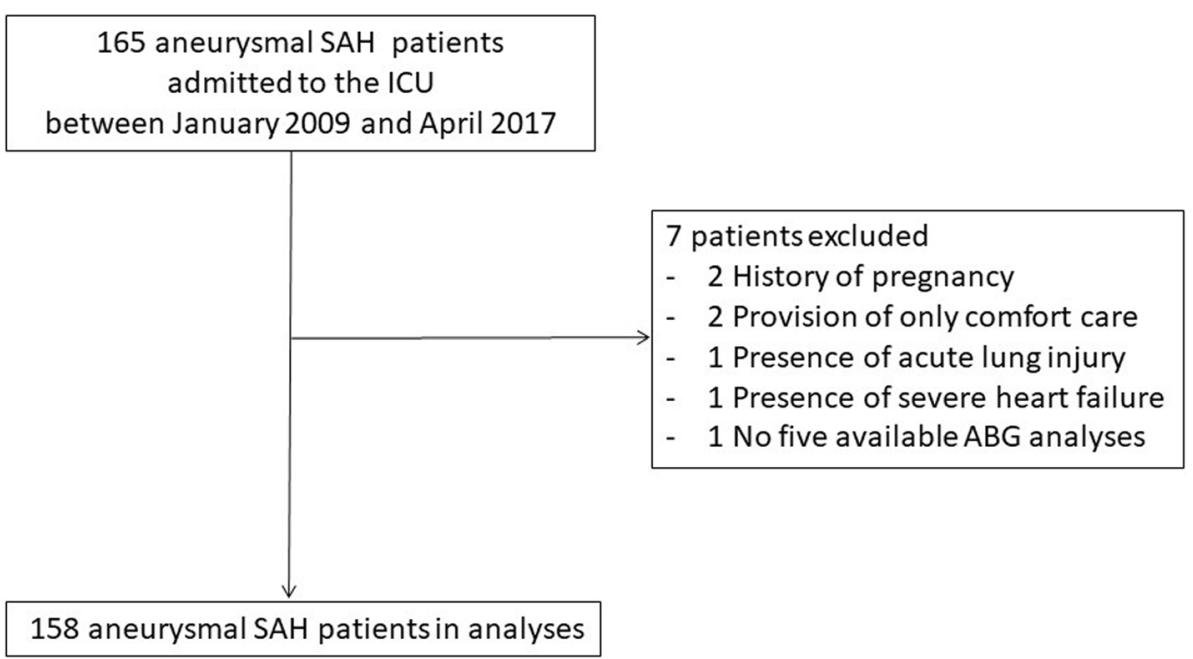

Fig. 1 Study flow diagram. ABG indicates arterial blood gas

periodic ABG monitoring was completed by day 14 . All patients were intubated prior to angiography and the initial treatment (surgical clipping or endovascular coiling) using a muscle relaxant. The muscle relaxant was discontinued after the completion of the initial treatment and was not used as ICU management thereafter. In mechanically ventilated patients, respiratory management usually involved the use of the spontaneous breathing mode (pressure support mode) with minimal support (i.e., continuous positive airway pressure or a pressure support level $\leq 5 \mathrm{~cm} \mathrm{H}_{2} \mathrm{O}$ ). Daily spontaneous breathing trials were not routinely performed. When a patient's condition stabilized, he/she was usually weaned off mechanical ventilation and extubated after the completion of the initial treatment.

\section{Data sampling}

The following data were collected: age, sex, Hunt and Kosnik (H\&K) grade, treatment modality (coil or clip), number of $\mathrm{PaCO}_{2}$ measurements, $\mathrm{PaCO}_{2}$ levels, maximum and minimum $\mathrm{PaCO}_{2}$ levels during the first 2 weeks in the ICU, serum lactate levels, use of mechanical ventilation, modified Rankin scale (mRS) score at hospital discharge, DCI rate, mechanical ventilation duration, ICU stay duration, hospital stay duration, and hospital mortality.

\section{Outcome measures}

The primary outcome was the association of abnormal $\mathrm{PaCO}_{2}$ with unfavorable neurological outcomes assessed using the mRS at hospital discharge [21]. The mRS is a measure of global disability and comprises the following seven outcome categories: no symptoms at all, no significant disability, slight disability, moderate disability, moderately severe disability, severe disability, and death. All the patients with SAH were evaluated in real time using the $\mathrm{mRS}$ at hospital discharge, and the findings were mentioned in their medical records. The neurological outcome was considered unfavorable when the mRS score was 3-6 and was considered favorable when the mRS score was $0-2$. The secondary outcome was the association of abnormal $\mathrm{PaCO}_{2}$ with the presence of DCI.

\section{Statistical analysis}

The patients were divided into two groups according to their neurological outcomes (unfavorable and favorable outcome groups). Descriptive statistics are used to summarize the demographic factors and baseline characteristics. The groups were compared using Student's $t$ test or the Mann-Whitney $U$ test, as deemed appropriate. Fisher's exact test was used to make the categorical comparisons. Alterations in the $\mathrm{PaCO}_{2}$ levels were examined separately for each clinical grade and $\mathrm{SAH}$ outcome. Univariate and multivariate analyses were performed to determine the independent predictors of unfavorable neurological outcomes. The covariates of age ( $>65$ years), sex (female), H\&K grade, treatment modality (coil or clip), maximum lactate levels during the first $24 \mathrm{~h}[4,8,22]$, and maximum and minimum $\mathrm{PaCO}_{2}$ levels during the first 2 weeks in the ICU were included in the multivariate analysis based on published reports [23, 24]. The MannWhitney $U$ test was used to estimate the receiver operating characteristic (ROC) curve and area under the curve (AUC). For each continuous variable, the cutoff value that had the best combination of sensitivity and specificity was identified. The patients were subdivided further into four groups according to the maximum and minimum $\mathrm{PaCO}_{2}$ levels during the first 2 weeks in the ICU. The statistical analyses were performed using EZR (Saitama Medical 
Center, Jichi Medical University, Saitama, Japan), a graphical user interface for R (The R Foundation for Statistical Computing, Vienna, Austria); more precisely, it is a modified version of $\mathrm{R}$ commander designed to add statistical functions that are frequently used in biostatistics [25]. A two-sided $p$ value $<0.05$ was considered statistically significant in all the analyses. Missing data were not replaced or estimated.

\section{Results}

\section{Baseline characteristics of the study population}

The study included 158 patients (mean age, 62.9 years; 52 men; Table 1). The median number of $\mathrm{PaCO}_{2}$ measurements per patient during the first 2 weeks in the ICU was 43. Unfavorable neurological outcomes were observed in $46.2 \%$ of the patients. Table 1 presents the comparisons of clinical characteristics between the unfavorable and favorable outcome groups. On univariate analysis, the groups significantly differed with regard to age $(p<0.01), \mathrm{H} \& \mathrm{~K}$ grade $(p<0.01)$, SD of $\mathrm{PaCO}_{2}$ levels $(p<0.01)$, and maximum $(p<0.01)$ and minimum $\mathrm{PaCO}_{2}$ levels $(p<0.01)$ during the first 2 weeks in the ICU. On comparing the unfavorable and favorable outcome groups, it was found that the unfavorable outcome group had a significantly longer median (interquartile range) mechanical ventilation duration (9 [2-16] days vs. 1 [1, 2] days, $p<0.01)$, ICU stay duration (17 [13-21] days vs. 14 [12-16] days, $p<0.01)$, and hospital stay duration (41 [26-74] days vs. 24 [21-30] days, $p<0.01$ ).

No significant differences in median $\mathrm{PaCO}_{2}$ levels were observed between the unfavorable and favorable outcome groups $(p=0.11)$; however, the unfavorable outcome group had significantly higher proportions of hypocapnia $\left(\mathrm{PaCO}_{2}\right.$ $<35 \mathrm{mmHg} ; p<0.01)$ and hypercapnia $\left(\mathrm{PaCO}_{2}>45 \mathrm{mmHg}\right.$; $p=0.02$ ) among all the blood gas analyses during the first 2 weeks in the ICU. The episodes of hypocapnia were not intentional, and most involved an associated $\mathrm{pH}$ level of $>7.45$ and not $<7.35$. The relationships between the neurological outcomes of each SAH severity (H\&K grades) and $\mathrm{PaCO}_{2}$ are presented in Additional file 1: Table S1. Although there was no significant difference in the median of $\mathrm{PaCO}_{2}$ or proportion of hypocapnia and hypercapnia across $\mathrm{H} \& \mathrm{~K}$ grades, there were significant differences in minimum $\mathrm{PaCO}_{2}$ levels and outcomes across $\mathrm{H} \& \mathrm{~K}$ grades.

\section{Alterations in $\mathrm{PaCO}_{2}$ levels during the first 2 weeks in the ICU according to neurological outcomes}

As Fig. 2 shows, during the early stage of hospitalization (days 1-5), $\mathrm{PaCO}_{2}$ levels were lower in the unfavorable outcome group than in the favorable outcome group. Subsequently, about 1 week after hospitalization (days 6-8), almost no differences in $\mathrm{PaCO}_{2}$ levels were found between the groups. However, in the late stage of hospitalization (days 9-14), $\mathrm{PaCO}_{2}$ levels were again lower in the unfavorable outcome group than in the favorable outcome group.

\section{Alterations in $\mathrm{PaCO}_{2}$ levels during the first 2 weeks in the ICU according to disease severity (H\&K grade)}

As Fig. 3 shows, during the early stage of hospitalization (days 1-5), $\mathrm{PaCO}_{2}$ levels were lower in patients with moderate-to-severe disease grade ( $\mathrm{H} \& \mathrm{~K}$ grades III-V) than in those with mild disease grade (H\&K grades I-II). However, after day 6, almost no differences in $\mathrm{PaCO}_{2}$ levels were found between the patient groups.

\section{Predictors of unfavorable neurological outcomes in patients with $\mathrm{SAH}$}

On multiple regression analysis (Table 2), unfavorable neurological outcomes were significantly associated with age, $H \& K$ grade, maximum lactate levels during the first $24 \mathrm{~h}$, and maximum (odds ratio [OR], 1.12; 95\% confidence interval $[\mathrm{CI}], 1.03-1.21 ; p<0.01)$ and minimum $\mathrm{PaCO}_{2}$ levels (OR, 0.81; 95\% CI, 0.72-0.92; $p<0.01)$.

\section{ROC curve analysis}

ROC curves of unfavorable neurological outcomes according to the maximum and minimum $\mathrm{PaCO}_{2}$ levels in the ICU were constructed. Table 3 presents the respective AUCs, sensitivities, and specificities for predicting unfavorable neurological outcomes. The optimal cutoff values for the maximum and minimum $\mathrm{PaCO}_{2}$ levels were 48.3 and $30.2 \mathrm{mmHg}$, respectively, during the first 2 weeks in the ICU.

\section{Association between $\mathrm{PaCO}_{2}$ levels and unfavorable neurological outcomes}

We found that $78.8 \%$ of patients with a maximum $\mathrm{PaCO}_{2}$ of $>48.3 \mathrm{mmHg}$ and a minimum $\mathrm{PaCO}_{2}$ of $<30.2 \mathrm{mmHg}$ had unfavorable neurological outcomes, whereas only $22.8 \%$ of patients who did not have either of these $\mathrm{PaCO}_{2}$ levels had unfavorable neurological outcomes (Fig. 4).

\section{Association between $\mathrm{PaCO}_{2}$ levels and $\mathrm{DCl}$}

DCI was observed in $14.6 \%$ of patients. The median period from admission to the occurrence of DCI was 8 (range, 7-9) days. The presence of DCI was confirmed during the first 2 weeks in the ICU. Additional file 1: Table S2 presents comparisons of the clinical characteristics between patients with DCI and those without DCI. On univariate analysis, there were no significant differences in age, sex, treatment modality, median $\mathrm{PaCO}_{2}$ levels, and proportions of hypocapnia and hypercapnia between patients with DCI and those without DCI, although the number of patients with DCI was relatively small. On the other hand, the maximum $\mathrm{PaCO}_{2}$ level, $\mathrm{SD}$ of $\mathrm{PaCO}_{2}$, and ICU and hospital stay durations were 
Table 1 Characteristics of the study population

\begin{tabular}{|c|c|c|c|c|}
\hline Variables & $\begin{array}{l}\text { All patients } \\
(N=158)\end{array}$ & $\begin{array}{l}\text { Unfavorable outcome } \\
\text { group }(N=73)\end{array}$ & $\begin{array}{l}\text { Favorable outcome } \\
\text { group }(N=85)\end{array}$ & $p$ value \\
\hline Age (years) & $62.9 \pm 15.9$ & $69.6 \pm 15.1$ & $57.1 \pm 14.4$ & $<0.01$ \\
\hline Sex (male) & $52(32.9)$ & $23(31.5)$ & $29(34.1)$ & 0.74 \\
\hline H\&K grade & & & & $<0.01$ \\
\hline 1 & $13(8.2)$ & $3(4.1)$ & $10(11.8)$ & \\
\hline$\|$ & $60(38.0)$ & $14(19.2)$ & $46(54.1)$ & \\
\hline III & $41(25.9)$ & $22(30.1)$ & $19(22.4)$ & \\
\hline IV & $29(18.4)$ & $23(31.5)$ & $6(7.1)$ & \\
\hline V & $15(9.5)$ & $11(15.1)$ & $4(4.7)$ & \\
\hline Treatment modality & & & & 0.27 \\
\hline Coil & $117(74.1)$ & $58(79.5)$ & $59(69.4)$ & \\
\hline Clip & $39(24.7)$ & $14(19.2)$ & $25(29.4)$ & \\
\hline $\begin{array}{l}\text { Number of arterial blood gas analyses on } \\
\text { days } 1-14\end{array}$ & $43[31-55]$ & $53[39-56]$ & $40[28-48]$ & $<0.01$ \\
\hline Median $\mathrm{PaCO}_{2}$ on days $1-14(\mathrm{mmHg})$ & $39.0[37.2-40.9]$ & $38.4[36.9-40.5]$ & $39.4[37.4-40.9]$ & 0.11 \\
\hline $\mathrm{SD}$ of $\mathrm{PaCO}_{2}$ on days $1-14$ & $3.63[2.75-4.60]$ & $4.05[3.58-5.20]$ & $2.97[2.45-3.95]$ & $<0.01$ \\
\hline $\begin{array}{l}\text { Proportion of } \mathrm{PaCO}_{2} \leq 30 \text { among all blood } \\
\text { gas analyses on days } 1-14(\%)\end{array}$ & $0[0-2]$ & $2[0-5]$ & $0[0-0]$ & $<0.01$ \\
\hline $\begin{array}{l}\text { Proportion of } \mathrm{PaCO}_{2}<35 \text { among all blood } \\
\text { gas analyses on days } 1-14(\%)\end{array}$ & $14[3-26]$ & $21[9-35]$ & 9 [2-22] & $<0.01$ \\
\hline $\begin{array}{l}\text { Proportion of } \mathrm{PaCO}_{2}>45 \text { among all blood } \\
\text { gas analyses on days } 1-14(\%)\end{array}$ & $4[0-16]$ & $7[2-18]$ & $2[0-12]$ & $<0.05$ \\
\hline Maximum $\mathrm{PaCO}_{2}$ level on days $1-14(\mathrm{mmHg})$ & $47.4[43.7-51.0]$ & $49.4[45.6-51.9]$ & $45.8[42.9-49.8]$ & $<0.01$ \\
\hline Minimum $\mathrm{PaCO}_{2}$ level on days $1-14(\mathrm{mmHg})$ & $31.0[28.7-33.8]$ & $29.4[26.2-32.7]$ & $31.7[30.2-34.5]$ & $<0.01$ \\
\hline Use of mechanical ventilation & $156(98.7)$ & $73(100)$ & $83(97.6)$ & 0.50 \\
\hline Modified Rankin scale score & & & & $<0.01$ \\
\hline 0 & $29(18.4)$ & $0(0.0)$ & $29(34.1)$ & \\
\hline 1 & $27(17.1)$ & $0(0.0)$ & $27(31.8)$ & \\
\hline 2 & $29(18.4)$ & $0(0.0)$ & $29(34.1)$ & \\
\hline 3 & $24(15.2)$ & $24(32.9)$ & $0(0.0)$ & \\
\hline 4 & $27(17.1)$ & $27(37.0)$ & $0(0.0)$ & \\
\hline 5 & $12(7.6)$ & $12(16.4)$ & $0(0.0)$ & \\
\hline 6 & $10(6.3)$ & $10(13.7)$ & $0(0.0)$ & \\
\hline $\mathrm{DCl}$ & $23(14.6)$ & $16(21.9)$ & $7(8.2)$ & $<0.05$ \\
\hline Mechanical ventilation duration & $2[1-9]$ & $9[2-16]$ & $1[1-2]$ & $<0.01$ \\
\hline ICU stay duration & 15 [12-19] & 17 [13-21] & $14[12-16]$ & $<0.01$ \\
\hline Hospital stay duration & $28[22-51]$ & $41[26-74]$ & $24[21-30]$ & $<0.01$ \\
\hline Hospital mortality & $10(6.3)$ & $10(13.7)$ & $0(0.0)$ & $<0.01$ \\
\hline
\end{tabular}

Data are presented as mean \pm standard deviation (SD), number (percentage), or median [interquartile range]

$H \& K$ Hunt and Kosnik, DCl Delayed cerebral ischemia, ICU Intensive care unit

significantly greater in patients with DCI than in those without DCI. In addition, DCI was associated with unfavorable neurological outcomes. On multiple regression analysis (Additional file 1: Table S3), DCI was significantly associated with the maximum $\mathrm{PaCO}_{2}$ level (OR, 1.1; 95\% CI, 1.02-1.19; $p<0.05$ ).
Alterations in $\mathrm{PaCO}_{2}$ levels during the first 2 weeks in the ICU according to the presence/absence of $\mathrm{DCI}$

As Fig. 5 shows, although the number of patients with DCI was relatively small, patients with DCI showed increased $\mathrm{PaCO}_{2}$ variability during the first 2 weeks in the ICU when compared with the findings in patients without DCI. 


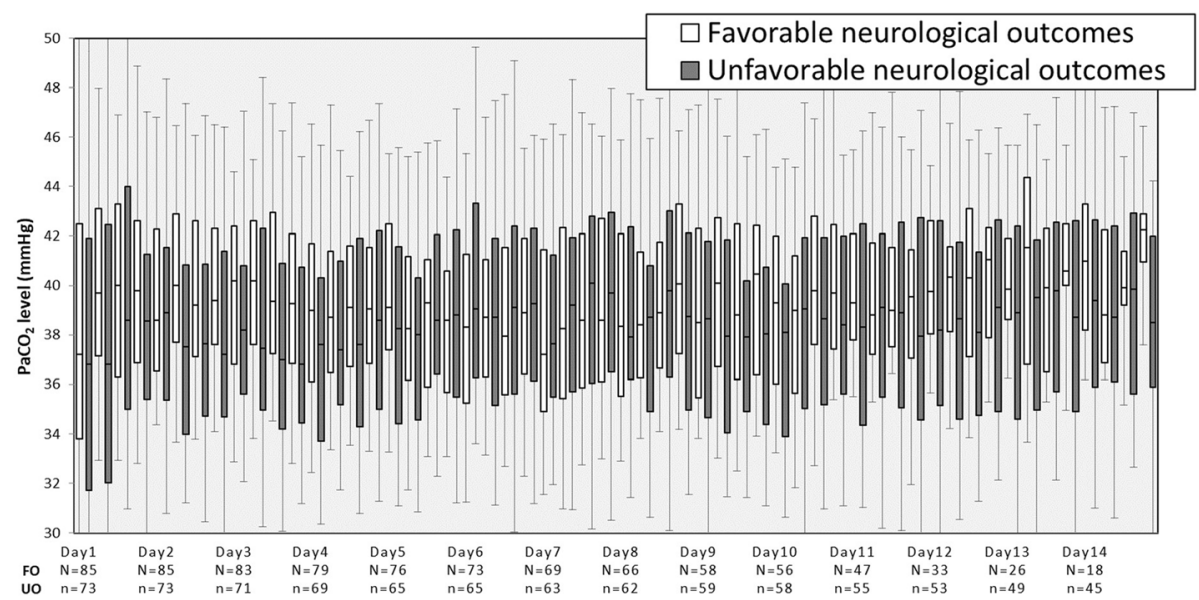

Fig. 2 Alterations in $\mathrm{PaCO}_{2}$ levels during the first 2 weeks in the intensive care unit according to neurological outcomes. The boxes represent the 25 th to 75 th percentile. The whiskers represent the 5th to 95th percentile. UO, unfavorable neurological outcomes; FO, favorable neurological outcomes

\section{Discussion}

In the present study, we demonstrated that both the maximum and minimum $\mathrm{PaCO}_{2}$ levels during ICU management were significantly associated with unfavorable neurological outcomes in patients with SAH. Moreover, we investigated the thresholds for both hypocapnia and hypercapnia to examine the target $\mathrm{PaCO}_{2}$ level during ICU management in patients with $\mathrm{SAH}$, which might help in further prospective studies with adjustment for factors, such as respiratory settings and sedation.

\section{Association between hypocapnia and neurological outcomes}

Several previous studies reported that hypocapnia was associated with poor neurological outcomes or DCI [14, 15].
Williamson et al. reported that severe hypocapnia, which was defined as $\mathrm{PaCO}_{2} \leq 30 \mathrm{mmHg}$, was significantly associated with poor neurological outcomes (OR, 4.52; $p<0.01$ ) [15], and this finding is consistent with our result. However, they reported that moderate hypocapnia, which was defined as $\mathrm{PaCO}_{2}<35 \mathrm{mmHg}$, was not independently associated with poor neurological outcomes (OR, $1.30 ; p=0.58$ ) [15]. Hypocapnia was previously shown to be associated with brain tissue hypoxia and poor outcomes in patients with TBI [26, 27]. Therefore, the current guidelines do not support the use of prophylactic and induced hypocapnia $\left(\mathrm{PaCO}_{2}<30 \mathrm{mmHg}\right)$ [28]. Consistent with these findings and guidelines, avoidance of hypocapnia, especially a $\mathrm{PaCO}_{2}$ level of $<30 \mathrm{mmHg}$, is presumed to be desirable in the management of patients with SAH.

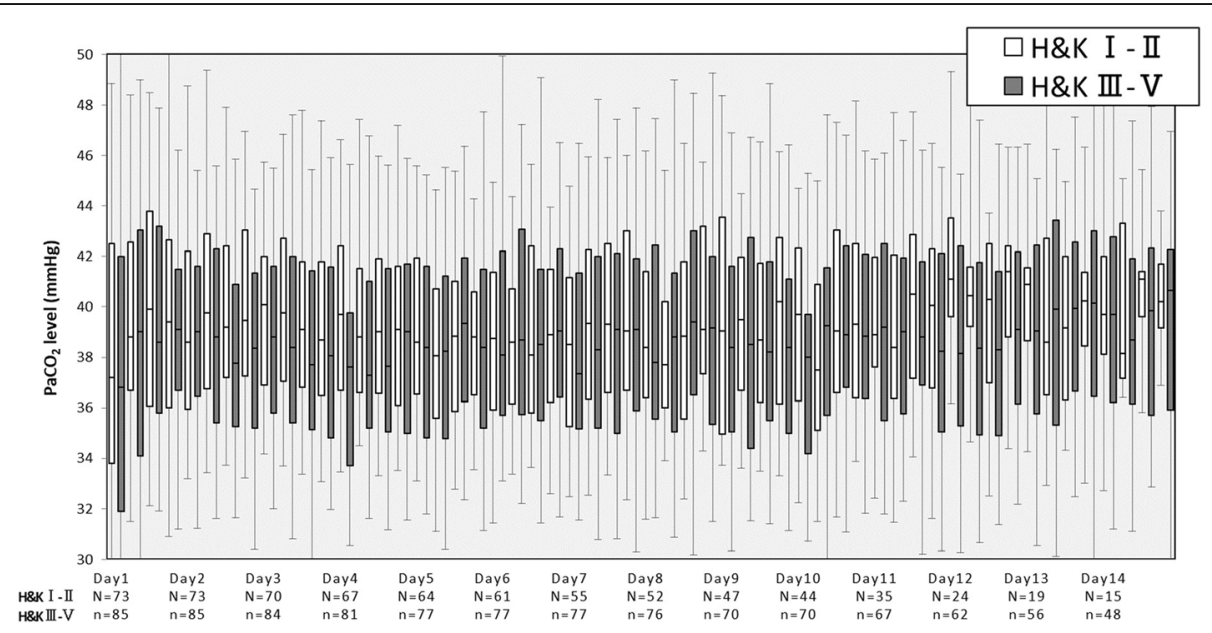

Fig. 3 Alterations in $\mathrm{PaCO}_{2}$ levels during the first 2 weeks in the intensive care unit according to the Hunt and Kosnik grade of subarachnoid hemorrhage. The boxes represent the 25 th to 75 th percentile. The whiskers represent the 5 th to 95 th percentile 
Table 2 Multivariate analysis of factors that influenced unfavorable outcomes

\begin{tabular}{|c|c|c|c|}
\hline Variables & OR & $95 \% \mathrm{Cl}$ & $p$ value \\
\hline Age $>65$ years & 7.62 & $2.97-19.60$ & $<0.01$ \\
\hline Sex (female) & 1.01 & $0.38-2.67$ & 0.98 \\
\hline H\&K grade & 2.43 & $1.53-3.87$ & $<0.01$ \\
\hline Treatment modality (clip) & 0.69 & $0.27-1.75$ & 0.43 \\
\hline $\begin{array}{l}\text { Maximum lactate levels during } \\
\text { the first } 24 \mathrm{~h}(\mathrm{mmol} / \mathrm{L})\end{array}$ & 1.34 & $1.02-1.76$ & $<0.05$ \\
\hline Maximum $\mathrm{PaCO}_{2}$ level $(\mathrm{mmHg})$ & 1.11 & $1.03-1.21$ & $<0.01$ \\
\hline Minimum $\mathrm{PaCO}_{2}$ level $(\mathrm{mmHg})$ & 0.82 & $0.73-0.93$ & $<0.01$ \\
\hline
\end{tabular}

OR odds ratio; $\mathrm{Cl}$ confidence interval, $H \& K$ Hunt and Kosnik

\section{Association between hypercapnia and neurological outcomes}

As shown in Fig. 2, on days 1-14, the 75th percentile of $\mathrm{PaCO}_{2}$ levels appeared to not be significantly different between the unfavorable and favorable outcome groups. This result indicated that some patients with unfavorable outcomes had higher $\mathrm{PaCO}_{2}$ levels with greater variation when compared with the findings in those with favorable outcomes. It remains unknown whether a hypercapnia strategy to avoid hypocapnia in patients with SAH is permitted. The association between hypercapnia and poor outcomes has been suggested to be secondary to hypercapnia- induced cerebral vasodilation, increased intracranial pressure, and decreased cerebral perfusion $[13,29,30]$. Alternatively, a previous report involving SAH patients with a poor clinical grade (Hunt/Hess III-V) investigated the association between controlled hypercapnia and CBF or brain tissue oxygen saturation $\left(\mathrm{StiO}_{2}\right)$ [10]. The report mentioned that although controlled hypercapnia of up to $60 \mathrm{mmHg}$ reproducibly increased $\mathrm{CBF}$ and $\mathrm{StiO}_{2}$, the $\mathrm{PaCO}_{2}$ reactivity of $\mathrm{CBF}$, which was calculated by dividing the change in CBF by the change in $\mathrm{PaCO}_{2}$, was the highest at $\mathrm{PaCO}_{2}$ levels between 40 and $50 \mathrm{mmHg}$ and was slightly decreased at higher $\mathrm{PaCO}_{2}$ levels. Impaired $\mathrm{PaCO}_{2}$ reactivity has been reported to be frequent after $\mathrm{SAH}$, particularly in patients with a poor clinical grade, and associated with DCI [31]. Considering our current data and the importance of $\mathrm{PaCO}_{2}$ reactivity and possibly the cerebral steal phenomenon, hypercapnia of up to approximately $50 \mathrm{mmHg}$ might be permitted as a therapeutic strategy. However, there are limited studies, and thus, further investigations are necessary.

\section{Association between $\mathrm{PaCO}_{2}$ levels and $\mathrm{DCl}$}

Several previous studies reported that hypocapnia was associated with DCI $[14,15]$. In our study, a small number of patients had DCI, and no significant association was noted between DCI and hypocapnia. According to our current data, hypercapnia or $\mathrm{PaCO}_{2}$ variability might have been associated with DCI. However, further studies are necessary.

\section{Mechanism of abnormal $\mathrm{PaCO}_{2}$ levels}

The mechanism of the association between abnormal $\mathrm{PaCO}_{2}$ levels and neurological outcomes is unknown, and it was difficult to discuss about the causal relationship of abnormal $\mathrm{PaCO}_{2}$ levels owing to the retrospective nature of our study as well as previous studies and the absence of adjustment for factors, such as respiratory settings and sedation [13]. However, severe brain injury following SAH itself might directly induce abnormal $\mathrm{PaCO}_{2}$ levels [15]. In the present study, we found that $22.8 \%$ of patients (13 patients) with $\mathrm{PaCO}_{2}$ levels within the cutoff range (30.2$48.3 \mathrm{mmHg}$ ) had unfavorable neurological outcomes. In these 13 patients, the mean age was relatively high $(70.4 \pm$ 11.4 years) and $69.2 \%$ (9 patients) had H\&K grades III-V. We concluded that these factors, besides the abnormal $\mathrm{PaCO}_{2}$ levels, could also affect the outcomes. Meanwhile, unfavorable neurological outcomes were noted in $78.8 \%$ of the patients with $\mathrm{PaCO}_{2}$ levels outside the cutoff range (26 patients). For these patients, we also determined the duration during which their $\mathrm{PaCO}_{2}$ levels were outside the range. ABG analyses represent $\mathrm{PaCO}_{2}$ level at a certain time point; we assumed that $\mathrm{PaCO}_{2}$ level among blood gas samples was linear. Although there was no significant difference among the neurological outcomes, the duration outside the cutoff range tended to be longer in the 26 patients with unfavorable neurological outcomes compared with the 7 patients with favorable neurological outcomes (33.8 $\pm 15.6 \mathrm{~h}$ vs. $25.1 \pm 9.7 \mathrm{~h}, p=0.17)$. Regarding this point, we concluded that a significant difference could have been noted if the number of patients was large. Accordingly, further detailed study regarding the influence of the duration during which the $\mathrm{PaCO}_{2}$ levels are outside the range on neurological outcomes seems to be necessary.

\section{Clinical implementation}

The findings of the present study collectively suggested that both hypocapnia and hypercapnia were associated with unfavorable neurological outcomes after SAH. Our

Table 3 Receiver operating characteristic curve analysis of maximum and minimum $\mathrm{PaCO}_{2}$ levels

\begin{tabular}{llllll}
\hline Variables & AUC & $95 \% \mathrm{Cl}$ & Optimal cutoff & Sensitivity & Specificity \\
\hline Maximum $\mathrm{PaCO}_{2}$ level & 0.641 & $0.55-0.73$ & $48.3 \mathrm{mmHg}$ & 58.9 & 68.2 \\
Minimum $\mathrm{PaCO}_{2}$ level & 0.696 & $0.61-0.78$ & $30.2 \mathrm{mmHg}$ & 60.3 & 74.1 \\
\hline
\end{tabular}

AUC area under the curve, $\mathrm{Cl}$ confidence interval 


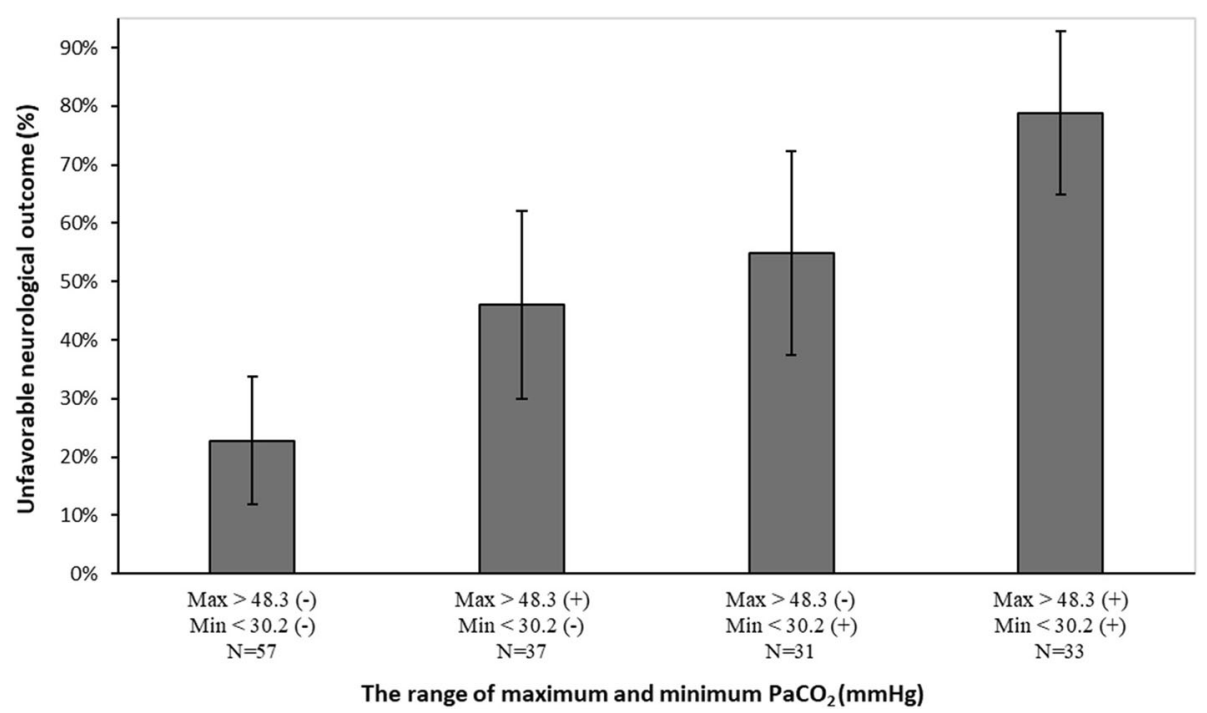

Fig. 4 Association between $\mathrm{PaCO}_{2}$ levels and unfavorable neurological outcomes. Error bars represent 95\% confidence intervals (Cls)

study design was not controlled intentionally, and a causal relationship was unclear. Our results should be regarded as hypothesis generating. Therefore, further prospective studies with adjustment for factors such as respiratory settings and sedation are necessary to determine a more appropriate $\mathrm{PaCO}_{2}$ target (30-40 or 40-50 $\mathrm{mmHg}$ ) and to evaluate the causal relationship of abnormal $\mathrm{PaCO}_{2}$ levels and the effectiveness of end-tidal $\mathrm{CO}_{2}$ monitoring in $\mathrm{CO}_{2}$ management. Moreover, our findings might indicate the issue of $\mathrm{PaCO}_{2}$ variability, and $\mathrm{PaCO}_{2}$ can fluctuate greatly similar to glucose $[3,32,33]$. Thus, the intentional control of $\mathrm{PaCO}_{2}$ might be beneficial, especially in the first $72 \mathrm{~h}$ after hemorrhage when early brain injury occurs [8].

\section{Limitations}

The present study had several limitations. First, this was a retrospective observational study conducted at a single center, and thus, there was potential selection bias. Moreover, uncontrolled confounding factors may have been present. Second, the neurological outcomes of patients after discharge were not assessed. Third, the possible impact of differences in the patient population, such as those brought about by comorbidities, on neurological outcomes could not be definitively excluded. Fourth, the vital signs, sedation dose, oxygen dose, end-tidal $\mathrm{CO}_{2}$ level, and specific mechanical ventilator settings, including the minute volume, fraction of inspired oxygen, and positive end-expiratory pressure during each ABG analysis,

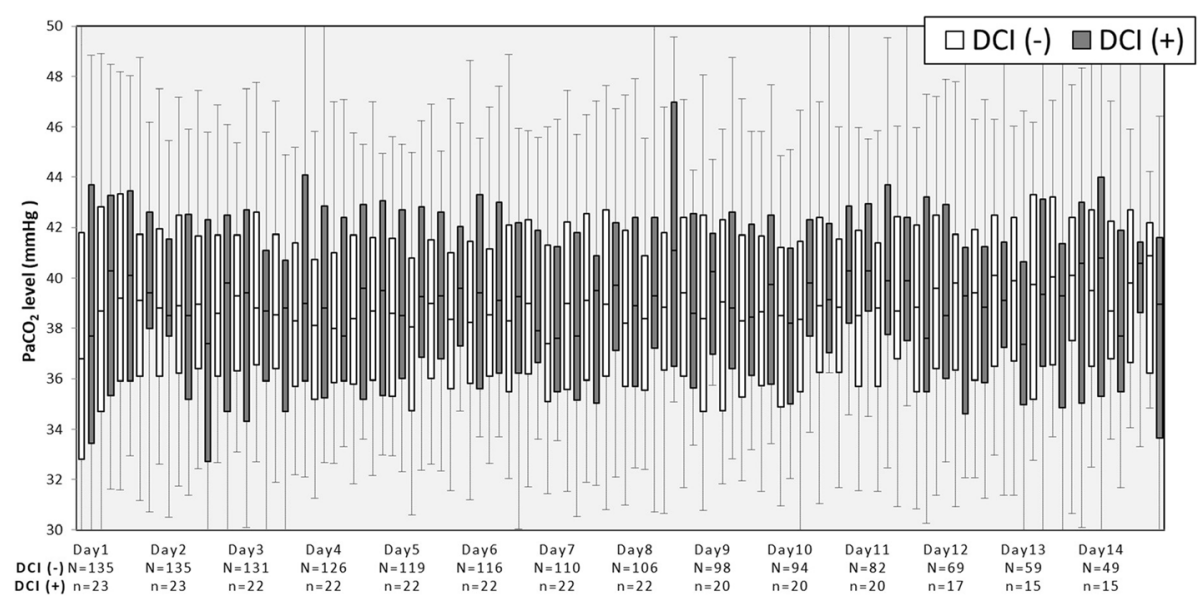

Fig. 5 Alterations in $\mathrm{PaCO}_{2}$ levels during the first 2 weeks in the intensive care unit according to presence/absence of DCl. The boxes represent the 25 th to 75 th percentile. The whiskers represent the 5th to 95th percentile 
were not sufficiently considered. Therefore, it was difficult to assess the causal relationship of abnormal $\mathrm{PaCO}_{2}$ levels and examine whether the $\mathrm{PaCO}_{2}$ levels obtained in this study were intentionally controlled. Fifth, the study sample size was relatively small. Sixth, as this study had a small number of patients with DCI, the association between DCI and outcomes was not sufficiently analyzed. Finally, as the current study examined the limited association between abnormal $\mathrm{PaCO}_{2}$ levels and neurological outcomes in patients with $\mathrm{SAH}$, the effect of the regulation of abnormal $\mathrm{PaCO}_{2}$ levels was not determined. Furthermore, as details of the causes of abnormal $\mathrm{PaCO}_{2}$ levels, such as inadequate use of sedatives, antipyretic agents, or muscle relaxants, and the oxygen concentration or pressure support during mechanical ventilation were not obtained owing to the retrospective nature of this study, we could not make definitive suggestions on the management of $\mathrm{PaCO}_{2}$ in a clinical setting. The results of our study should be regarded as hypothesis generating. Therefore, further prospective studies, including randomized controlled trials, are required to confirm the effects of abnormal $\mathrm{PaCO}_{2}$ levels on neurological outcomes in patients with $\mathrm{SAH}$.

\section{Conclusions}

We found that hypocapnia and hypercapnia during ICU management in patients with SAH were significantly associated with unfavorable neurological outcomes. Further prospective studies are required to validate our findings and explore their clinical implications. Our findings may provide a scientific rationale for these future prospective studies.

\section{Additional file}

Additional file 1: Table S1. Baseline characteristics of the study population across H\&K grades. Table S2. Association between $\mathrm{PaCO}_{2}$ levels and DCI (univariate analysis). Table S3. Multivariate analysis of factors that influenced DCl. (DOCX $36 \mathrm{~kb}$ )

\begin{abstract}
Abbreviations
ABG: Arterial blood gas; CBF: Cerebral blood flow; Cl: Confidence interval; DCI: Delayed cerebral ischemia; H\&K: Hunt and Kosnik; ICU: Intensive care unit; OR: Odds ratio; $\mathrm{PaCO}_{2}$ : Arterial carbon dioxide tension; SAH: Subarachnoid hemorrhage; TBI: Traumatic brain injury
\end{abstract}

\section{Acknowledgements}

We are grateful to all the physicians and the nurses at the study site for their crucial contributions to the successful completion of this study.

\section{Funding}

Not applicable.

\section{Availability of data and materials}

The datasets analyzed during the current study are available from the corresponding author on reasonable request.
Authors' contributions

SY, TH, TO, TM, and YK designed the experiments; SY and TH wrote the manuscript; TN, KK, TT, TM, and YK supervised the work; and all the authors read and approved the final manuscript.

\section{Authors' information}

Highest academic degrees:

SY, M.D.; TH (Councilor of the Japanese society of Intensive Care Medicine), M.D., Ph.D.; TO, M.D.; TN, M.D., Ph.D.; KK, M.D., Ph.D.; TT, M.D., Ph.D.; TM, M.D., Ph.D.; YK (Executive Director of the Japanese society of Intensive Care Medicine, Associate Editor of Journal of Intensive Care), M.D., Ph.D.

\section{Ethics approval and consent to participate}

Owing to the retrospective nature of the study, the IRB waived the requirement for patient consent.

\section{Consent for publication}

Not applicable.

\section{Competing interests}

The authors declare that they have no competing interests.

\section{Publisher's Note}

Springer Nature remains neutral with regard to jurisdictional claims in published maps and institutional affiliations.

\section{Author details}

${ }^{1}$ Department of Cardiorenal and Cerebrovascular Medicine, Kagawa University Hospital, 1750-1 Ikenobe, Miki, Kita, Kagawa 761-0793, Japan. ${ }^{2}$ Department of Critical and Emergency Medicine, St. Luke's International Hospital, 9-1 Akashi-cho, Chuo-ku, Tokyo 104-8560, Japan. ${ }^{3}$ Emergency Medical Center, Kagawa University Hospital, 1750-1 Ikenobe, Miki, Kita, Kagawa 761-0793, Japan. ${ }^{4}$ Department of Neurosurgery, Kagawa University Hospital, 1750-1 Ikenobe, Miki, Kita, Kagawa 761-0793, Japan.

Received: 5 October 2018 Accepted: 4 December 2018

Published online: 17 December 2018

\section{References}

1. Grasso G, Alafaci C, Macdonald RL. Management of aneurysmal subarachnoid hemorrhage: state of the art and future perspectives. Surg Neurol Int. 2017:8:11.

2. Hop JW, Rinkel GJ, Algra A, van Gijn J. Case-fatality rates and functional outcome after subarachnoid hemorrhage: a systematic review. Stroke. 1997: 28:660-4.

3. Okazaki T, Hifumi T, Kawakita K, Shishido H, Ogawa D, Okauchi M, et al. A strong independent predictor of neurological outcomes in aneurysmal subarachnoid hemorrhage. J Intensive Care Med. 2018:33:189-95.

4. Okazaki T, Hifumi T, Kawakita K, Shishido H, Ogawa D, Okauchi M, et al. Serial blood lactate measurements and its prognostic significance in intensive care unit management of aneurysmal subarachnoid hemorrhage patients. J Crit Care. 2017:41:229-33.

5. Okazaki T, Hifumi T, Kawakita K, Shishido H, Ogawa D, Okauchi M, et al. Target serum sodium levels during intensive care unit management of aneurysmal subarachnoid hemorrhage. Shock. 2017:48:558-63.

6. Egawa S, Hifumi T, Kawakita K, Okauchi M, Shindo A, Kawanishi M, et al. Impact of neurointensivist-managed intensive care unit implementation on patient outcomes after aneurysmal subarachnoid hemorrhage. J Crit Care. 2016:32:52-5.

7. Okazaki T, Hifumi T, Kawakita K, Shishido H, Ogawa D, Okauchi M, et al. Association between dexmedetomidine use and neurological outcomes in aneurysmal subarachnoid hemorrhage patients: a retrospective observational study. J Crit Care. 2018:44:111-6.

8. Okazaki T, Kuroda Y. Aneurysmal subarachnoid hemorrhage: intensive care for improving neurological outcome. J Intensive Care. 2018;6:28.

9. Kinoshita K. Traumatic brain injury: pathophysiology for neurocritical care. J Intensive Care. 2016;4:29.

10. Westermaier T, Stetter C, Kunze E, Willner N, Holzmeier J, Weiland J, et al. Controlled hypercapnia enhances cerebral blood flow and brain tissue oxygenation after aneurysmal subarachnoid hemorrhage: results of a phase 1 study. Neurocrit Care. 2016;25:205-14. 
11. Pynnonen L, Falkenbach $P$, Kamarainen A, Lonnrot K, Yli-Hankala A, Tenhunen J. Therapeutic hypothermia after cardiac arrest - cerebral perfusion and metabolism during upper and lower threshold normocapnia. Resuscitation. 2011:82:1174-9.

12. Floyd TF, Clark JM, Gelfand R, Detre JA, Ratcliffe S, Guvakov D, et al. Independent cerebral vasoconstrictive effects of hyperoxia and accompanying arterial hypocapnia at 1 ATA. J Appl Physiol (1985). 2003;95:2453-61.

13. Roberts BW, Karagiannis $P$, Coletta M, Kilgannon JH, Chansky ME, Trzeciak S. Effects of $\mathrm{PaCO} 2$ derangements on clinical outcomes after cerebral injury: a systematic review. Resuscitation. 2015;91:32-41.

14. Solaiman O, Singh JM. Hypocapnia in aneurysmal subarachnoid hemorrhage: incidence and association with poor clinical outcomes. J Neurosurg Anesthesiol. 2013;25:254-61.

15. Williamson CA, Sheehan KM, Tipirneni R, Roark CD, Pandey AS, Thompson $B G$, et al. The association between spontaneous hyperventilation, delayed cerebral ischemia, and poor neurological outcome in patients with subarachnoid hemorrhage. Neurocrit Care. 2015:23:330-8.

16. Carrera E, Schmidt JM, Fernandez L, Kurtz P, Merkow M, Stuart M, et al. Spontaneous hyperventilation and brain tissue hypoxia in patients with severe brain injury. J Neurol Neurosurg Psychiatry. 2010;81:793-7.

17. Committee for Guidelines for Management of Aneurysmal Subarachnoid Hemorrhage, Japanese Society on Surgery for Cerebral Stroke. Evidencebased guidelines for the management of aneurysmal subarachnoid hemorrhage. English Edition. Neurol Med Chir (Tokyo). 2012;52:355-429.

18. Connolly ES Jr, Rabinstein AA, Carhuapoma JR, Derdeyn CP, Dion J, Higashida RT, et al. Guidelines for the management of aneurysmal subarachnoid hemorrhage: a guideline for healthcare professionals from the American Heart Association/American Stroke Association. Stroke. 2012;43: 1711-37.

19. Eastwood GM, Schneider AG, Suzuki S, Peck L, Young H, Tanaka A, et al Targeted therapeutic mild hypercapnia after cardiac arrest: a phase II multi-centre randomised controlled trial (the CCC trial). Resuscitation. 2016; 104:83-90.

20. Frontera JA, Fernandez A, Schmidt JM, Claassen J, Wartenberg KE, Badjatia $N$, et al. Defining vasospasm after subarachnoid hemorrhage: what is the most clinically relevant definition? Stroke. 2009;40:1963-8.

21. Banks $J$, Marotta CA. Outcomes validity and reliability of the modified Rankin scale: implications for stroke clinical trials: a literature review and synthesis. Stroke. 2007;38:1091-6.

22. van Donkelaar CE, Dijkland SA, van den Bergh WM, Bakker J, Dippel DW, Nijsten MW, et al. Early circulating lactate and glucose levels after aneurysmal subarachnoid hemorrhage correlate with poor outcome and delayed cerebral ischemia: a two-center cohort study. Crit Care Med. 2016; 44:966-72.

23. Wartenberg KE, Schmidt JM, Claassen J, Temes RE, Frontera JA, Ostapkovich $\mathrm{N}$, et al. Impact of medical complications on outcome after subarachnoid hemorrhage. Crit Care Med. 2006;34:617-23 quiz 624

24. Lantigua H, Ortega-Gutierrez S, Schmidt JM, Lee K, Badjatia N, Agarwal S, et al. Subarachnoid hemorrhage: who dies, and why? Crit Care. 2015:19:309.

25. Kanda Y. Investigation of the freely available easy-to-use software 'EZR' for medical statistics. Bone Marrow Transplant. 2013;48:452-8.

26. Muizelaar JP, Marmarou A, Ward JD, Kontos HA, Choi SC, Becker DP, et al. Adverse effects of prolonged hyperventilation in patients with severe head injury: a randomized clinical trial. J Neurosurg. 1991;75:731-9.

27. Davis DP, Idris AH, Sise MJ, Kennedy F, Eastman AB, Velky T, et al. Early ventilation and outcome in patients with moderate to severe traumatic brain injury. Crit Care Med. 2006;34:1202-8.

28. Bratton SL, Chestnut RM, Ghajar J, McConnell Hammond FF, Harris OA, Hartl $R$, et al. Guidelines for the management of severe traumatic brain injury. XIV Hyperventilation J Neurotrauma. 2007;24:S87-90.

29. Roberts BW, Kilgannon JH, Chansky ME, Mittal N, Wooden J, Trzeciak S. Association between postresuscitation partial pressure of arterial carbon dioxide and neurological outcome in patients with post-cardiac arrest syndrome. Circulation. 2013;127:2107-13.

30. Falkenbach P, Kamarainen A, Makela A, Kurola J, Varpula T, Ala-Kokko T, et al. Incidence of iatrogenic dyscarbia during mild therapeutic hypothermia after successful resuscitation from out-of-hospital cardiac arrest. Resuscitation. 2009;80:990-3.

31. Carrera E, Kurtz P, Badjatia N, Fernandez L, Claassen J, Lee K, et al. Cerebrovascular carbon dioxide reactivity and delayed cerebral ischemia after subarachnoid hemorrhage. Arch Neurol. 2010;67:434-9.
32. Egi M, Bellomo R, Stachowski E, French CJ, Hart G. Variability of blood glucose concentration and short-term mortality in critically ill patients. Anesthesiology. 2006;105:244-52.

33. Krinsley JS. Glycemic variability: a strong independent predictor of mortality in critically ill patients. Crit Care Med. 2008:36:3008-13.

\section{Ready to submit your research? Choose BMC and benefit from:}

- fast, convenient online submission

- thorough peer review by experienced researchers in your field

- rapid publication on acceptance

- support for research data, including large and complex data types

- gold Open Access which fosters wider collaboration and increased citations

- maximum visibility for your research: over $100 \mathrm{M}$ website views per year

At BMC, research is always in progress.

Learn more biomedcentral.com/submissions 